\title{
Normal proximal and delayed distal conduction in the pudendal nerves of patients with idiopathic (neurogenic) faecal incontinence
}

\author{
ES KIFF, ${ }^{*}$ M SWASH ${ }^{*} \dagger$ \\ From St Mark's Hospital* and The London Hospital, † London, UK
}

SUMMARY The latency of the response in the external anal sphincter muscle following transcutaneous stimulation of the cauda equina at the L1 vertebral level was measured in nine women with neurogenic faecal incontinence (mean $7.3 \mathrm{SD} 0.7 \mathrm{~ms}$ ) and 11 normal subjects (mean $5.6 \mathrm{SD}$ $0.6 \mathrm{~ms})(\mathrm{p}=0.01)$. There was no difference in conduction velocity between the L1 and L4 vertebral levels thus supporting the suggestion that conduction delay in faecal incontinence occurs distally.

In patients with idiopathic faecal incontinence there is evidence of neurogenic damage to the puborectalis and external anal sphincter muscles. ${ }^{1-3} \mathrm{We}$ have recently demonstrated an increased latency in the response of the external anal sphincter muscle to trans-rectal stimulation of the pudendal nerve at the level of the ischial spine in these patients. ${ }^{4}$ Marsden, Merton and Morton ${ }^{5}$ measured the latency of the response in this muscle in two normal subjects following transcutaneous spinal stimulation and we have now applied this method to investigate our patients with faecal incontinence.

Parks, Swash and Urich suggested in 1977 that because the pudendal nerves are tightly bound by connective tissue on leaving the pelvis and entering the pudendal canal, descent of the pelvic floor during childbirth or defaecation straining might result in stretch injury to these nerves.' Henry, Parks and Swash $^{6}$ have shown that the amount of descent of the pelvic floor measured in incontinent patients with the descending perineum syndrome would result in a $20 \%$ increase in the length of the pudendal nerves-more than sufficient to cause injury. ${ }^{7}$ We wished to know if the increased latency found on transrectal stimulation of the pudendal nerves in incontinent patients was limited to the distal portion of the pudendal nerves, as would be expected with this entrapment/stretch hypothesis, or whether con-

Address for reprint requests: Dr M Swash, The London Hospital, Whitechapel, London E1 1BB, UK.

Received 11 November 1983 and in revised form 17 January 1984. Accepted 30 January 1984 duction was delayed in the whole length of these nerves suggesting a more proximal lesion.

\section{Patients and methods}

Nine women aged $28-71$ years (mean $50 \cdot 9$, SD $16 \cdot 9$ years) presenting with neurogenic faecal incontinence were studied, and the results compared with those obtained from 11 normal volunteers or patients attending for follow-up of benign colonic pathology, or minor ano-rectal conditions, aged $18-58$ years (mean $42 \cdot 9$, SD $13 \cdot 2$ years).

\section{Manometry and EMG}

The incontinent patients were all examined by ano-rectal manometry using methods previously standardised in our laboratory. ${ }^{3}$ In addition concentric needle and single fibre EMG studies of the external anal sphincter muscle were carried out. The rectified, integrated EMG activity recorded by a concentric EMG needle in the external anal sphincter muscle was measured during one second of a maximal voluntary sphincter contraction using a Medelec L6 integrator with a Medelec MS6 EMG apparatus. The motor unit fibre density was calculated using a single fibre EMG technique. ${ }^{2}$

\section{Pudendal nerve terminal motor latency}

Digitally directed pudendal nerve terminal motor latency measurement was made using a method developed from the technique of electroejaculation described by Brindley for use in patients with impotence due to paraplegia. The device consisted of a rubber finger stall having two bare metal stimulating electrodes at its tip, and two metal surface electrode plates for recording mounted $3 \mathrm{~cm}$ proximally, at the base of the finger stall. The anode was $5 \mathrm{~mm}$ in diameter, the cathode being less than $1 \mathrm{~mm}$ in order to improve localisation. A ground electrode was applied to the thigh. The device, mounted on the index finger, was 
inserted into the rectum and the ischial spine palpated. Square wave stimuli of $0.1 \mathrm{~ms}$ duration and 30 volts were given at one second intervals and the tip of the device slowly moved until the sphincter was felt to contract firmly around the base of the finger and the motor unit action potential on the oscilloscopte of the EMG apparatus achieved a maximum amplitude. A supramaximal stimulus, usually 50 volts, was then given and two consecutive series of five recordings were made on the paper printout of the Medelec MS6 EMG apparatus. The procedure was then repeated on the opposite side of the pelvis. The latency of the response was measured on the paper recordings from the onset of the stimulus to the onset of the response. This method has been described in more detail elsewhere. ${ }^{4}$

\section{Spinal stimulation}

The latency of the response in the external anal sphincter muscle following transcutaneous stimulation of the two pudendal nerves at the level of L1 was measured in all 20 subjects. In addition the latencies were measured following stimulation 9-13 cm distally (at L4) in four normal subjects and six incontinent patients thereby allowing calculation of conduction time (fig).

Transcutaneous stimulation was achieved using the method described by Marsden and colleagues. ${ }^{5}$ A single impulse of 800 volts, decaying with a time constant of 50 $\mu s$ was delivered through two saline-soaked pads with the cathode firmly held over the spinous process of either the first or fourth lumbar vertebra, and the anode $5 \mathrm{~cm}$ cranially. The response in the external anal sphincter muscle was recorded through 2 poles of a $3 \mathrm{~cm}$ long 3 pole telephone-jack plug electrode lubricated with electrode jelly, situated in the anal canal and connected to a Medelec MS6 EMG machine. The third pole was connected to ground. The onset of the stimulus triggered the oscilloscope of the EMG machine. The latency was measured on the paper printout from the onset of the stimulus to the onset of the response. The shortest distance from the site of stimulation to the anal verge was measured. From these two measurements the conduction time was calculated and this value has been used to compare the two groups. The conduction time from the first to fourth lumbar levels was calculated by subtraction in 10 subjects.

\section{Results}

\section{ANORECTAL MANOMETRY}

Resting tone in the nine incontinent patients ranged from 0 to $70 \mathrm{~cm}$ (mean $31.4 \pm 21.5 \mathrm{~cm}$ ) water. The normal range in our unit is $60-100 \mathrm{~cm}$ (mean $80 \mathrm{~cm}$ ) water. Maximal voluntary contraction pressures ranged from 10 to $80 \mathrm{~cm}$ (mean $42.9 \pm 28.2 \mathrm{~cm}$ ) water in the incontinent group (normal range 80 $200 \mathrm{~cm}$, mean $120 \mathrm{~cm}$ water).

\section{CONCENTRIC NEEDLE EMG}

The rectified integrated activity measured during one second of maximal voluntary contraction of the external anal sphincter muscle ranged from 8 to 36 $\mu \mathrm{Vs}$ (mean $21.0 \pm 11.6 \mu \mathrm{Vs}$ ); the normal range in
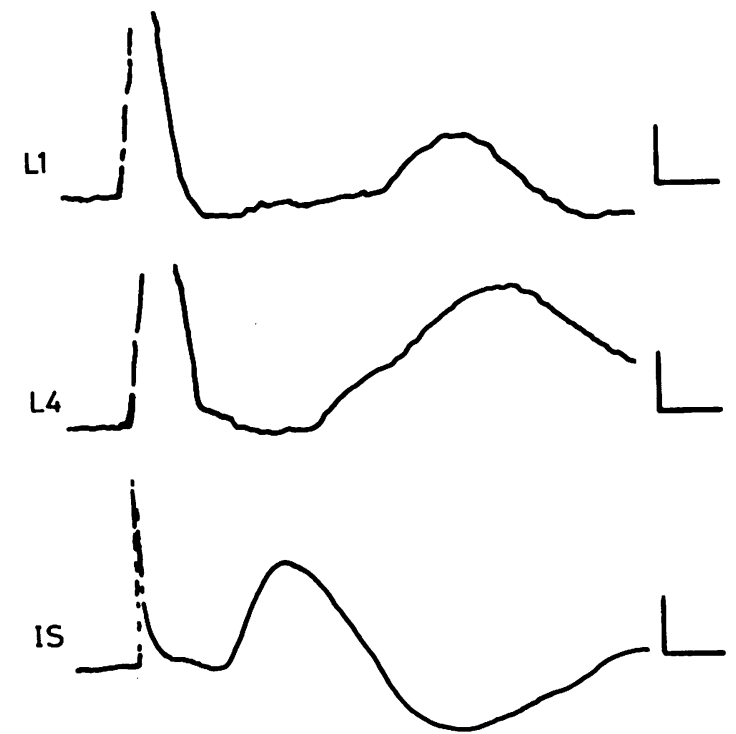

Fig Motor unit action potentials in the external anal sphincter muscle following transcutaneous spinal stimulation at the L1 and L4 levels and following transrectal stimulation of the pudendal nerve at the level of the ischial spine. Scale: horizontal axis 2 ms. Vertical axis 50 rvolts, $L 1$ and L4; 500 pvolts IS (ischial spine).

this muscle is $40-130 \mu \mathrm{Vs}$ (mean $67 \cdot 0 \pm 21 \mu \mathrm{Vs}){ }^{4}$

\section{SINGLE FIBRE EMG}

The fibre density in the external anal sphincter muscle of the nine incontinent patients ranged from 1.7 to $2 \cdot 1$ (mean $1.9 \pm 0.3$ ); normal 1.3 to $1.6{ }^{2}$

PUDENDAL NERVE TERMINAL MOTOR LATENCY In the nine incontinent patients the latency on the right side ranged from 2.4 to $3.2 \mathrm{~ms}$ (mean $2.7 \pm 0.3$ $\mathrm{ms})$ and on the left side ranged from 2.4 to $3.0 \mathrm{~ms}$ (mean $2.7 \pm 0.2 \mathrm{~ms}$ ). The mean terminal pudendal nerve motor latency, derived from both sides, was $2.7 \pm 0.2 \mathrm{~ms}$. The normal mean value, based on 28 subjects, was $2 \cdot 0 \pm 0.3 \mathrm{~ms}^{4}$

\section{SPINAL STIMULATION: LATENCY AND CONDUCTION VELOCITY}

The latencies of the external anal sphincter response evoked by spinal stimulation at L1 and L4 in normal subjects and in patients with faecal incontinence are shown in table 1 . These latencies represent conduction in the pudendal nerves from spinal and cauda equina stimulation. The difference in mean latency between normal subjects and patients with faecal incontinence following stimulation at the $\mathrm{L} 1$ site was $1.7 \mathrm{~ms}$, and at the $\mathrm{L} 4$ site, $1.5 \mathrm{~ms}$ respectively.

In normal subjects the distance to the anal verge 
Table 1 Pudendal nerve motor latency and conduction velocity following stimulation at L1 and L4 levels in normal subjects and patients with faecal incontinence

\begin{tabular}{|c|c|c|c|c|}
\hline \multirow[t]{2}{*}{ Stimulus Site } & \multicolumn{2}{|l|}{ Latency (ms) } & \multicolumn{2}{|c|}{ Conduction velocity $\left(\mathrm{ms}^{-1}\right) \ddagger$} \\
\hline & $\begin{array}{l}\text { Normal } \\
\text { mean } S D \text { range }\end{array}$ & $\begin{array}{l}\text { Faecal incontinence } \\
\text { mean SD range }\end{array}$ & $\begin{array}{l}\text { Normal } \\
\text { mean } S D \text { range }\end{array}$ & $\begin{array}{l}\text { Faecal incontinence } \\
\text { mean SD range }\end{array}$ \\
\hline L1 & $\begin{array}{l}5.60 .6 \dagger 4.6-6.5 \\
(n=11)\end{array}$ & $\begin{array}{l}7.30 .7 \dagger 6.4-8.4 \\
(n=9)\end{array}$ & $\begin{array}{l}61 \cdot 24 \cdot 6 \dagger 56-71 \\
(n=11)\end{array}$ & $\begin{array}{l}46.65 .6 \dagger 39.56 \\
(n=9)\end{array}$ \\
\hline L4 & $\begin{array}{l}4 \cdot 10 \cdot 4 \\
(n=4)\end{array} 3 \cdot 7-4 \cdot 8$ & $\begin{array}{l}5 \cdot 61.0 \\
(n=6)\end{array}$ & $\begin{array}{l}58.89 .9 \quad 48-73 \\
(n=4)\end{array}$ & $\begin{array}{l}43.47 \cdot 0 \quad 35-55 \\
(\mathrm{n}=6)\end{array}$ \\
\hline
\end{tabular}

*Data from Kiff and Swash. ${ }^{4}$

†Differences significant $(p=0.01)$ Wilcoxon Rank Sum Test.

¥The calculated conduction velocities from spinal stimulation include the slower terminal latency times, measured from direct pudendal stimulation, and therefore represent an approximation of the true conduction velocity.

Table 2 Conduction velocity $\left(\mathrm{ms}^{-1}\right)$ in the pudendal nerves between the L1 and L4 stimulation sites in normal subjects and patients with faecal incontinence

\begin{tabular}{lll}
\hline & \multicolumn{2}{l}{ Conduction velocity $\left(\mathrm{ms}^{-1}\right)$} \\
\cline { 2 - 3 } & Mean $\pm S D$ & Range \\
\hline $\begin{array}{l}\text { Normal }(\mathrm{n}=4) \\
\text { Faecal incontinence } \\
(\mathrm{n}=6)\end{array}$ & $52 \cdot 3 \pm 4 \cdot 5$ & $50-59$ \\
\hline
\end{tabular}

from the L1 stimulation site ranged from 28 to 39 $\mathrm{cm}$ (mean $34.4 \pm 3.6 \mathrm{~cm}$ ), and from the L4 stimulation site from 23 to $29 \mathrm{~cm}$ (mean $25 \cdot 2 \pm 3 \cdot 1 \mathrm{~cm}$ ). In patients with faecal incontinence the distance to the anal verge from the $\mathrm{L} 1$ stimulation site ranged from 32 to $37 \mathrm{~cm}$ (mean $33.4 \pm 1.5 \mathrm{~cm}$ ), and from the $\mathrm{L} 4$ stimulation site ranged from 24 to $27 \mathrm{~cm}$ (mean $24 \cdot 3$ $\pm 1 \cdot 1 \mathrm{~cm}$ ). These measurements were used to calculate conduction velocities as shown in table 1 .

The motor latency was measured from both the $\mathrm{L} 1$ and $\mathrm{L} 4$ levels in four normal subjects and six patients with faecal incontinence. The conduction velocity along the pudendal nerves between these two sites of stimulation was calculated by subtraction. These results are shown in table 2 .

\section{Discussion}

This study has confirmed the feasibility of transcutaneous stimulation of neurons within the spinal canal at the L1 vertebral level, ${ }^{5}$ and of the cauda equina at the $\mathrm{L} 4$ vertebral level in patients. The latency of the response in the external anal sphincter muscle in normal subjects is less than $7 \mathrm{~ms}$. We have shown that this response is similar to that evoked by stimulation of the distal part of the pudendal nerve, in the pelvis, but with a correspondingly longer latency. ${ }^{4}$

Transcutaneous spinal stimulation of the pudendal nerve has two advantages. Firstly, by stimulating at two sites, a measurement of conduction time be- tween the two sites, and thus of motor nerve conduction velocity, can be made, although there will be slight inaccuracy due to the variability and spread of the stimulating discharge through the tissues at the two sites. Secondly, for the purposes of distal motor latency measurement the site of stimulation is unimportant, provided that it is distal to the cell body of the motor neurons. We have derived the conduction velocity in the pudendal nerve between the $\mathrm{L} 1$ and L4 stimulation sites by calculation (table 2). We used length measurements taken from the $\mathrm{L} 1$ and L4 vertebral spines to the anal verge respectively.

The latency of the response evoked in the external anal sphincter muscle following spinal cord stimulation at L1 suggests that any monosynaptic component of the anal reflex must occur at a latency of at least $11 \mathrm{~ms}$ in the normal subject. Marsden and colleagues, in two male subjects, calculated a somewhat larger value. ${ }^{5}$ Earlier estimates of the latency of the anal reflex in our laboratory ${ }^{10}$ based on electrical stimulation of the perianal skin, suggested a shorter latency (about $8.5 \mathrm{~ms}$ ) for the first component of this reflex; these experiments gave erroneous results in that the response evoked in the external anal sphincter muscle was contaminated by direct excitation of the muscle by current spread from the stimulating electrode..$^{1-13}$

Following spinal stimulation there was a significant increase in the latency in the incontinent patients compared with the normal subjects, confirming our results using transrectal stimulation in which we found an increased distal pudendal motor latency. ${ }^{4}$ The increased latency following spinal stimulation in incontinent patients was similar whether the stimulation was applied at the L1 level (mean increase $1.7 \mathrm{~ms}$ ) or the $\mathrm{L} 4$ level (mean increase $1.5 \mathrm{~ms}$ ) and, in the relatively small number of patients studied, there was no significant difference in conduction velocity between these two sites when the incontinent patients and normal subjects were compared (table 2 ). These results suggest that 
in patients with neurogenic faecal incontinence, delay in conduction occurs in the distal segment of the pudendal nerve rather than within the spinal canal.

The distal part of the pudendal nerve, from the site of intra-pelvic stimulation to the external anal sphincter muscle, is about $9 \mathrm{~cm}$ long (Kiff, unpublished observations). The variability in the latency of the response in this muscle to transrectal pudendal nerve stimulation in patients with neurogenic faecal incontinence may reflect either the severity of damage to the pudendal nerve or the proximity of the site of stimulation to the actual site of nerve damage. A conduction delay of this order of magnitude is consistent with entrapment of the pudendal nerve at the point of angulation around the ischial spine as it passes through the sacrospinous ligament. Since this might be amenable to surgical decompression this possibility requires further study.

Transcutaneous stimulation of the cauda equina and spinal cord, although not painful, is more unpleasant than transrectal stimulation of the pudendal nerve and it provides no extra clinical information in the investigation of patients with faecal incontinence. This new method may, however, be useful in investigating disorders of the pelvic floor other than faecal incontinence, such as chronic anal pain, perineal descent and rectal prolapse, in which there may also be a neurogenic factor, and in the evaluation of patients with other lesions in the lumbo-sacral plexus or nerve roots, or in the cauda equina.

We thank the late Sir Alan Parks, Dr PA Merton and $\mathrm{Mr} \mathrm{HB}$ Morton for their encouragment in this work, and the St Mark's Foundation for financial support.

\section{References}

' Parks AG, Swash M, Urich H. Sphincter denervation in anorectal incontinence and rectal prolapse. Gut 1977; 18:656-65.

${ }^{2}$ Neill ME, Swash M. Increased motor unit fibre density in the external anal sphincter muscle in anorectal incontinence: a single fibre EMG study. $J$ Neurol Neurosurg Psychiatry 1980;43:343-7.

${ }^{3}$ Neill ME, Parks AG, Swash M. Physiological studies of the pelvic floor in idiopathic faecal incontinence and rectal prolapse. Br J Surg 1981;68:531-6.

${ }^{4}$ Kiff ES, Swash M. Slowed conduction in the pudendal nerves in idiopathic (neurogenic) faecal incontinence. Br J Surg (in press)

${ }^{5}$ Marsden CD, Merton PA, Morton HB. The latency of the anal reflex. J Neurol Neurosurg Psychiatry 1978;41:813-8.

${ }^{6}$ Henry MM, Parks AG, Swash M. The anal reflex in idiopathic faecal incontinence; an elctrophysiological study. Br J Surg 1980;67:781-3.

${ }^{7}$ Sunderland S. Nerves and Nerve Injuries. 2nd ed. Edinburgh: Churchill-Livingstone, 1978:62-6.

${ }^{8}$ Brindley GS. Electroejaculation: its technique, neurological implications and uses. $J$ Neurol Neurosurg Psychiatry 1981;44:9-18.

${ }^{9}$ Henry MM, Swash M. Assessment of pelvic floor disorders and incontinence by electrophysiological recordings of the anal reflex. Lancet 1978;1:1290-1.

${ }^{10}$ Swash M. The neuropathology of idiopathic faecal incontinence. In: Smith WT, Cavanagh JB, eds. Recent Advances in Neuropathology. Edinburgh: Churchill-Livingstone, 1982:2.

$"$ Swash M. Early and late components in the human anal reflex.J Neurol Neurosurg Psychiatry 1982;45:767-9.

12 Pedersen E, Klemar B, Schroder HD, Torring J. Anal sphincter responses after perianal electrical stimulation. J Neurol Neurosurg Psychiatry 1982;45:770-3.

${ }^{13}$ Vodusek DB, Janko M, Lokar J. Direct and reflex responses in perineal muscles on electrical stimulation. J Neurol Neurosurg Psychiatry 1983;46:67-71. 